Revista Eletrônica de Farmácia

Eletronic Journal of Pharmacy

ISSN 1808-0804

doi $10.5216 /$ ref.v16.51041

Artigo Original

\title{
Viabilidade in vitro de leveduras armazenadas à temperatura am- biente
}

\section{In vitro viability of yeasts stored at room temperature}

\section{Viabilidad in vitro de levaduras almacenadas a temperatura ambiente}

\author{
MENEZES, Ralciane de Paula ${ }^{1}$. PEDROSO, Reginaldo dos Santos ${ }^{1 *}$. \\ ${ }^{1}$ Curso Técnico em Análises Clínicas, Escola Técnica de Saúde, Universidade Federal de Uberlândia - ESTES/UFU \\ *rpedroso@ufu.br
}

Resumo. Introdução. O armazenamento de isolados fúngicos, especialmente de leveduras, é importante para estudos de sensibilidade a antifúngicos ou outros testes complementares ao diagnóstico laboratorial, especialmente daqueles que ocorrem a partir de sítios como sangue e líquidos de cavidades corporais fechadas. Objetivo. Avaliar a viabilidade de leveduras dos gêneros Candida e Cryptococcus armazenadas em água destilada, solução salina fisiológica e BHI-glicerol, mantidas à temperatura ambiente. Material e Métodos. Foram analisados 404 isolados de leveduras, sendo 354 isolados de espécies de Candida e 50 de Cryptococcus neoformans/gattii, que foram armazenados em caldo infusão de cérebro-coração (BHI)-glicerol, água destilada e solução salina fisiológica, em temperatura ambiente. Resultados. Dos isolados de Candida spp. foram recuperados 100/178 (56,2\%) isolados a partir de água destilada, 90/97 (92,8\%) isolados a partir de solução salina fisiológica e 63/79 (79,7\%) a partir do BHI-glicerol. Dos isolados de Cryptococcus spp. armazenados em BHI-glicerol foram recuperados $30 / 50(60 \%)$ dos isolados. Conclusão. Para laboratórios com pouca demanda em exames micológicos, em que ocorrem poucos isolamentos de leveduras, especialmente do gênero Candida, o armazenamento em solução salina parece ser alternativa melhor que em água destilada.

Palavras-chave: Candida albicans. Cryptococcus. Manutenção.

\begin{abstract}
Introduction. The storage of fungal isolates, mainly yeast isolates, is important for studies of antifungal sensitivity or other laboratory tests and diagnosis, especially those isolated from anatomical sites such as blood and liquids from closed body cavities. Aim. To evaluate the viability of yeasts of Candida spp. and Cryptococcus spp. stored in distilled water, physiological saline solution and brain-heart infusion broth (BHI)-glycerol at room temperature. Material and methods. 404 yeast isolates were analyzed: 354 isolates of Candida spp. and 50 of Cryptococcus neoformans / gattii, which were stored in brain-heart infusion broth (BHI)-glycerol, distilled water and physiological saline at room temperature. Results. Were recovered $100 / 178(56.2 \%)$ Candida spp. isolated from distilled water, 90/97 (92.8\%) isolated from physiological saline solution and 63/79 $(79.7 \%)$ from BHI-glycerol. Of the isolates of Cryptococcus spp. stored in BHI-glycerol were recovered $30 / 50(60 \%)$ isolates. Conclusion. Laboratories with little demand for mycological exams, in which there are few yeast isolations, especially Candida species, storage in physiological saline is a better alternative than in distilled water.

Key-words: Candida albicans. Cryptococcus. Maintenance.
\end{abstract}

Resumen. Introducción. Una necesidad actual además del diagnóstico de laboratorio es el almacenamiento de aislados fúngicos, especialmente aquellos que aparecen en sitios anatómicos como sangre y líquidos de cavidades corporales cerradas. Objetivo. Evaluar la viabilidad de las levaduras del género Candida y Cryptococcus almacenadas en agua destilada, solución salina fisiológica y BHI-glicerol, mantenidas a temperatura ambiente. Material y Métodos. Se analizaron un total de 404 aislados de levadura, siendo 354 aislados de especies de Candida y 50 de Cryptococcus neoformans / gattii, que se almacenaron en caldo infusión de cerebro-corazón (BHI)-glicerol, agua destilada y solución salina fisiológica a temperatura ambiente. Resultados. De los aislados de Candida spp. se recuperaron 100/178 (56.2\%) aislados a partir de agua destilada, 90/97 (92.8\%) a partir de la solución salina fisiológica y 63/79 (79.7\%) de BHI-glicerol. De los aislados de Cryptococcus spp. almacenados en $\mathrm{BHI}$-glicerol se recuperaron 30/50 (60\%). Conclusión. Para laboratorios con demanda reducida en exámenes micológicos, en los que hay pocos aislamientos de levadura, especialmente especies de Candida, el almacenamiento en solución salina fisiológica parece ser una buena alternativa.

Palabras-clave: Candida albicans. Cryptococcus. Mantenimiento. 


\section{Introdução}

A ocorrência de candidíase invasiva e criptococose em pacientes internados e imunocomprometidos tem se revelado cada vez mais frequente, seja em serviços de alta complexidade ou hospitais menores(1). Isso resulta em maior trabalho para o setor de micologia dos laboratórios de análises clínicas, requerendo preparo adequado dos técnicos que, além do isolamento em cultura, precisam conhecer e executar técnicas para identificação dessas espécies fúngicas(2).

Uma necessidade atual, além do diagnóstico laboratorial, é o armazenamento dos isolados fúngicos, especialmente quando eles ocorrem a partir de sítios como sangue e outros de cavidade fechada (líquidos cefalorraquidiano, pericárdico e ascítico, por exemplo), para possíveis estudos futuros, como testes de sensibilidade aos antifúngicos $(3,4$, $5,6,7)$.

As condições de manutenção devem ser aquelas que mantenham, tanto quanto possível, as características fisiológicas e genéticas do microrganismo, de forma que permaneçam estáveis a virulência, patogenicidade e padrão de respostas a antifúngicos $(5,6,7,8)$.

Os métodos de conservação mais utilizados em laboratórios clínicos e de pesquisa são conservação em água destilada, conservação em óleo mineral, por congelamento (freezer ou nitrogênio líquido) entre $-60^{\circ} \mathrm{C} \mathrm{a}-135^{\circ} \mathrm{C}$ ou a $-18^{\circ} \mathrm{C}$ ou a $-20^{\circ} \mathrm{C}$, liofilização e ágar Sabouraud contidos em tubos, por repiques a cada três ou mais meses, a depender das condições de armazenamento e temperatura de manutenção(4). A escolha do método pelo laboratório depende da demanda, disponibilidade de recursos, tempo desejável para armazenamento e disponibilidade de recursos humanos para manipulação.

O objetivo deste estudo foi avaliar a viabilidade de leveduras dos gêneros Candida e Cryptococcus armazenadas em água destilada, solução salina fisiológica e infusão de cérebro e coração (do inglês, brain heart infusion [BHI])glicerol, mantidas em temperatura ambiente.

\section{Material e Métodos}

Amostras. Foram analisados 404 isolados de leveduras, sendo 354 isolados de espécies de Candida e 50 de Cryptococcus neoformans/gattii. Todas as leveduras foram de isolamentos humanos, incluindo de colonização bucal (espécies de Candida) e clínicos isolados a partir de sangue (maioria Candida spp.) e liquor (maioria Cryptococcus spp.), armazenadas no Laboratório do Curso Técnico em Análises Clínicas, da Escola Técnica de Saúde, da Universidade Federal de Uberlândia.

Armazenamento. Os armazenamentos foram feitos em frascos de $2 \mathrm{~mL}$, de fundo cônico, e tampa de pressão (tipo Eppendorff ${ }^{\circledR}$ ) e cada frasco continha inicialmente 1 $\mathrm{mL}$ de água destilada estéril ou solução salina fisiológica $(\mathrm{NaCl} 0,9 \%[\mathrm{~m} / \mathrm{v}])$ ou BHI-glicerol, em temperatura ambiente (a média de temperatura anual em Uberlândia-Minas Gerais varia de $15,4^{\circ} \mathrm{C}$ a $27,7^{\circ} \mathrm{C}$, conforme dados encontrados no site https://pt.climate-data.org/location/2896/, acesso em 07/07/2017). A transferência para os frascos foi realizada a partir de uma cultura recente da levedura ( 24 a 48 horas, incubadas em temperatura de $30^{\circ} \mathrm{C}$ ), na qual foi utilizada uma alça calibrada descartável de 10 microlitros para coletar uma colônia da levedura e homogeneizar nos frascos. Os isolados de espécies de Candida foram mantidos em frascos contendo água destilada esterilizada, solução salina fisiológica esterilizada e BHI-glicerol, e os de Cryptococcus spp. em BHI-glicerol somente. $\mathrm{O}$ armazenamento foi feito durante 42 meses (3,5 anos), de modo que após esse tempo foi realizada a tentativa de recuperação para verificar a viabilidade.

Viabilidade. O material contido nos frascos foi ressuspenso utilizando agitador tipo vórtex e, em seguida, foram retirados 100 microlitros da suspensão de cada isolado e espalhados em superfície de ágar Sabouraud dextrose $4 \%$, incubados por até uma semana em temperatura $30^{\circ} \mathrm{C}(+/-$ $\left.2{ }^{\circ} \mathrm{C}\right)$.

Análise. Após o período de incubação foi observado o crescimento de colônias de leveduras. Os resultados são apresentados em valores absolutos e relativos e discutidos de acordo com os métodos possíveis para preservação.

\section{Resultados e discussão}

A maioria dos isolados apresentaram-se viáveis, e foram recuperados após o repique em meio de cultura. Para Candida spp. a maior frequência de viabilidade foi observada entre as leveduras conservadas em solução salina fisiológica $(92,8 \%)$, conforme mostrado na Tabela 1 .

Tabela 1 - Frequência de leveduras viáveis após armazenamento em água destilada, solução salina fisiológica e BHI-glicerol durante 42 meses.

\begin{tabular}{ccccccc}
\hline Levedura & $\begin{array}{c}\text { Método de } \\
\text { armazenamento }\end{array}$ & \multicolumn{2}{c}{ Viáveis } & Não viáveis & Total \\
& & $\mathrm{n}$ & $\%$ & $\mathrm{n}$ & $\%$ & \\
\hline Cryptococcus spp. & BHI-glicerol & 30 & 60 & 20 & 40 & 50 \\
Candida spp. & Água destilada & 100 & 56,2 & 78 & 43,8 & 178 \\
& Salina fisiológica & 90 & 92,8 & 7 & 7,2 & 97 \\
& BHI-glicerol & 63 & 79,7 & 16 & 20,3 & 79 \\
\hline
\end{tabular}

As técnicas de conservação de leveduras in vitro são diversificadas, e cada laboratório pode adotar aquela que melhor lhe convém, de acordo com os recursos disponíveis e os objetivos do armazenamento. Para a escolha da técnica de conservação, deve-se levar em consideração o espaço físico para armazenamento, a disponibilidade de geladeiras e freezers, temperatura ambiente no local, meios de cultura disponíveis e recipientes adequados, além do custo total, pessoal técnico para gerenciamento e controle do estoque, 
e, ainda, o tempo de armazenamento.

De modo geral, parece consenso que na escolha do método, deve-se optar por aquele que seja capaz de manter as características fenotípicas, genotípicas e de patogenicidade dos isolados. Poucos estudos relatam a importância desse fato, e tentaram analisar a capacidade de manutenção daquelas características in vitro $(5,6)$, constatando que, na maioria dos casos, as características e/ou fatores de virulência são mantidos. No entanto, conforme observações dos autores, a preservação das variáveis analisadas é espécie-meio de conservação dependente.

Se a opção for por meios de cultura como ágar contidos em tubos, deve-se optar por meios que contenham somente glicose e minimizem o risco de alterações durante o crescimento, como seleção de mutantes. Alguns microrganismos podem produzir quantidade excessiva de ácido acético, e alternativas podem ser utilizadas, como acrescentar carbonato de cálcio para neutralizar o ácido(4).

Meios líquidos como água destilada e solução salina esterilizadas podem ser úteis, de baixo custo e necessitam de pouco espaço no laboratório. Como são substâncias inertes e capazes de manter a viabilidade sem oferecer condições para a célula se multiplicar, isso diminuiria a probabilidade de mutação $(3,4,6)$. No presente estudo, quando comparadas a viabilidade obtida entre água destilada e solução salina fisiológica, a segunda mostrou-se mais eficiente, sugerindo que salina é capaz de preservar a viabilidade por mais tempo.

$\mathrm{O}$ armazenamento em BHI-glicerol possibilitou a recuperação de cerca de $80 \%$ dos isolados. Silva et al.(5) mostraram que, em congelamento por 3 a 4 anos, $99 \%$ dos isolados foram recuperados. No presente estudo, quando o BHI-glicerol foi utilizado para armazenar em temperatura ambiente, foram recuperados percentagem maior de isolados de Candida que de Cryptococcus. Esse fato pode ser devido às particularidades dos dois grupos de microrganismos, em que Candida poderia apresentar maior resistência às alterações microambientais, e teriam maior capacidade adaptativa que Cryptococcus. Resultados obtidos por Kirsop (9) mostraram a variação de viabilidade entre diferentes gêneros de fungos mantidos nas mesmas condições. A conservação em BHI-glicerol nas condições realizadas, no entanto, parece não justificar o armazenamento nesse meio à temperatura ambiente, considerando os custos e o grau de recuperação das leveduras não ser tão eficiente quanto aquela observada em salina fisiológica. As técnicas de armazenamento em larga escala, em nitrogênio líquido, freezer $-70{ }^{\circ} \mathrm{C}$ e liofilizado apresentam, no entanto, a vantagem de permitir a conservação dos isolados por um tempo maior( 3 , 4).

Esses resultados sugerem que armazenamento em solução isotônica parece prolongar a viabilidade. Talvez estudos considerando soluções tampão possam apresentar resultados semelhantes, especialmente quando não há disponibilidade de um freezer no laboratório. No entanto, parece conveniente realizar estudos controlados e comparativos, com água destilada estéril, salina fisiológica estéril e outros possíveis conservantes, que possam ser utilizados para o armazenamento de leveduras, comparando a viabilidade de um mesmo isolado ou cepa nos diferentes meios.

\section{Conclusão}

Concluindo, para laboratórios com pouca demanda de isolados de leveduras, especialmente do gênero Candida, o armazenamento em solução salina parece ser uma alternativa melhor que em água destilada esterilizada.

\section{Referências}

1.Alexander BA. Diagnosis of fungal infection: new technologies for the mycology laboratory. Transpl. Infect. Dis. 2002;4 Suppl.3:32-7.

2. Fischer G, Dott W. Quality assurance and good laboratory practice in the mycological laboratory - compilation of basic techniques for the identification of fungi. Int. J. Hyg. Environ. Health. 2002;205(6):433-42.

3. Kirsop BE, Sneli JJS. Maintenance of microorganisms: a manual of laboratory methods. London: Academic Press; 1984.

4. Yarrow D. Method for the isolation, maintenance and identification of yeasts. In: Kurtzman CP, Fell JW, editors. The yeasts: a taxonomic study. 4th Ed. New York: Elsevier; 1998. p. 77-100.

5. Silva JO, Costa PP, Reche SHC. Manutenção de leveduras por congelamento a $-20^{\circ} \mathrm{C}$. Rev. Bras. Anal. Clin. 2008;40(1):73-4.

6. Barcelo KL, Costa KRC, Ferreira JC, Candido RC. Biotype stability of Candida albicans isolates after culture storage determined by randomly amplified polymorphic DNA and phenotypical methods. Mycoses. 2010;53(6): 468-74.

7. Arendrup MC, Meletiadis J, Mouton JW, Lagrou K, Hamal P, Guinea J; Subcommittee on Antifungal Susceptibility Testing (AFST) of the ESCMID European Committee for Antimicrobial Susceptibility Testing (EUCAST). EUCAST antifungal MIC method for yeasts. Method for the determination of broth dilution minimum inhibitory concentrations of antifungal agents for yeasts. EUCAST E. DEF 7.3.1. 2017.

8. Kurtzman CP, Fell JW, Boekhout T, Robert V. Methods for isolation, phenotypic characterization and maintenance of Yeasts. In: Kurtzman CP, Fell JW, editors. The yeasts: a taxonomic study. New York: Elsevier; 2011. p. 87-110.

9. Kirsop B. Maintenance of yeasts by freeze-drying. J. Inst. Brew. 1955; 61:466-71. 